\title{
Integrated BOM model oriented to manufacturing process of complex product
}

\author{
Lin Lin ${ }^{1,}$, Xiaobing Liu ${ }^{1}$, Wei Mu², Hongguang Bo ${ }^{1, b}$, Dongjuan $\mathrm{Xue}^{3}$ \\ ${ }^{1}$ Faculty of Management and Economics, Dalian University of Technology, Dalian 116024,China \\ ${ }^{2}$ CSR Qingdao Sifang Co., Ltd. Qingdao 266111,China \\ ${ }^{3}$ Dalian Ocean University, Dalian 116023, China \\ aemail: to_linlin@mail.dlut.edu.cn, bemail: hgbo@dlut.edu.cn
}

Keywords: Integrated Bill of Material; Complex Product; Business Process

\begin{abstract}
The static bill of material data and dynamic bill of process data need to be integrated during manufacturing process of complex product, in order to wholly control the workpiece of workshop and systematically consider material requirements planning and enterprise resource planning. This paper constructed an integrated BOM model based on production plan, which is described by a sequence, and generic production structure is introduced to represent diverse needs. Finally, the paper analyzes the general machining case of "suspension beam" parts assembly production in a complex products manufacturing enterprise, validating the practicality and effectiveness of integrated BOM model.
\end{abstract}

\section{Introduction}

Production schedules of complex products need real-time to scroll or rearrange due to some uncertain disturbance and variables in the manufacturing process. To track the status of dynamic processes, material implementation of workshop manufacturing process is the primary factor that should be taken into consideration for complex products. The workshops have many assembly processes when the parts assemble into components, so the materials ready on scheduled time and completeness of manufacturing materials must be guaranteed. In addition, management concept of integrated BOM based on production plan should be established, and more generic information of components production process which is related to the production plan and production process should be added during production process of complex product.

\section{Concept of integrated BOM based on production plan}

Yunkung Chung [1] proposed a conceptual BOM data model in 1994. The correlation among the product family in the complex product manufacturing enterprises is getting stronger [2] [3]. Integrated BOM can effectively solve the problem of production planning in the mentioned case. A complex product variant is allowed to regulate by integrated BOM via the description of multi-level BOM, in which each layer has some options, and it can show the relationship of raw materials accessories which is required among different types of goods.

In the manufacturing process of complex workpieces, it is necessary to integrate material contents in the BOM with corresponding operations in the BOP in order to reflect the flow of material in the production process and to achieve effective control of workpieces in the level of the production workshops [4] [5]. In order to integrate the product structure data with manufacturing process information, this paper builds an integrated BOM model based on production plans to deal with product diversity and plan implementation dynamics in the production process of complex product.

Integrated BOM model can closely connect materials with process of material, production status of materials, processing time, the assembly relations and the use of resources, thus ensure that the materials can be meet as schedule changing in the production process, and the product can also be 
customized to meet customer requirements for diversity at the same time. Aimed at the production process, integrated BOM model can describe operation sequence of a middleware or a finished product, and it also can represent information of materials and resources for each operation. Production planning BOM builds directly connection with the component materials through the parent products, but integrated BOM model establishes contact with component materials by corresponding operations of manufacturing the parent products in the BOP.

\section{Integrated BOM Modelling}

The concept of generic production structure is introduced to illustrate the diversity of complex product that can impact materials replacement and represent the demand of product diversity with the help of the relevant properties. Figure 1 shows the integrated BOM structure of the bogie based on generic diversity structure.

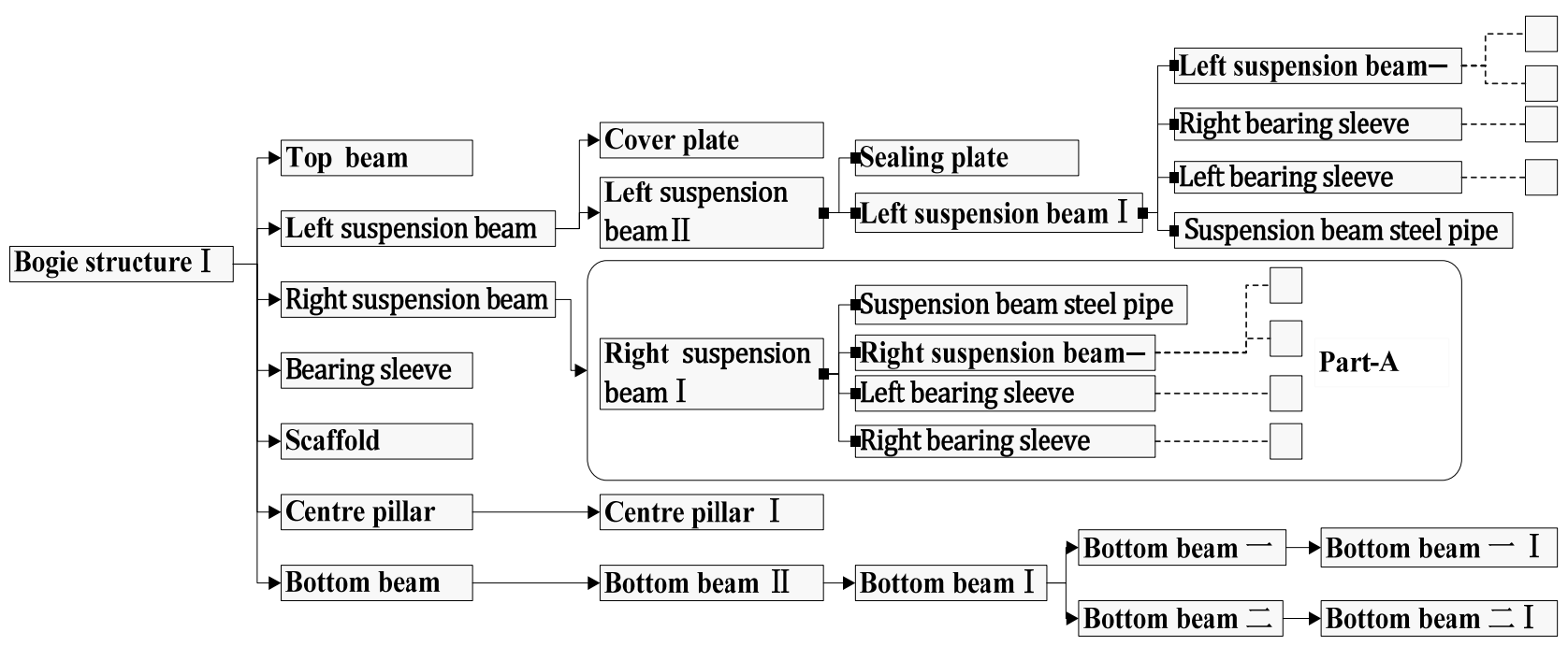

Fig.1. Integrated BOM structure

All product variants of a product family share a common structure. Decomposition tree structure reflects the basic structure of the final product configuration, and different public product structure are distinguished by different sets and their relationship. Generally, each BOM node has a set of properties that is related to product diversity [6], so the diversity parameters is defined. The parameters of child nodes can be inherited from the parent nodes, and different parameters indicate the difference between product variants.

A sequence can be used to represent aforementioned integrated BOM model, denoted as $\left(Z_{s} S_{s}, M C_{2}, C_{\nu}, O_{s}, E, E\right)$. I is the set of general items in the integrated BOM model; $S$ is the set of general production schedules; $M C$ is the set of machining centers; $C$ is production capacity of machining centers; $O$ is set of machining operations; $F$ is assembly relationships of integrated BOM; $E$ is the set of real-time components process state.

(1) General Item I. A universal product family represents the diversity of product family, and the products may be the final products, middleware, subassemblies or components. Each generic product $I_{i}$ includes a list of diversity parameters $\left\{P_{L_{i}}\right]$, and the set of possible values for each parameter is $\left\{p_{t j}\right\}$. The particular variants of generic products can be obtained by selecting valid values $\left\{p_{t j}\right\}$ for each diversity parameter $\left\{P_{t}\right]$, which is $t_{t}=\left\{p_{t \rightarrow 2}\right\}$. To express completely consistency and compatibility of information during the whole manufacturing process, this paper expands the connotation of general products further and uses the concept of general item to represent similar item sets of product family. An item can be either a final product, subassembly, middleware and component or it can also be a task plan, an affiliation (assembly relationship) or a machining operation. For example, the frame $\left(I_{2}, I_{2}, I_{3}\right)$ is the three separate variants, constituting a generic item which represents the sets of these variants, that is $l=\left\{l_{1}, l_{2}, I_{\Xi}\right\}$. 
(2) General production schedule S. S indicates process variants of the operational tasks plan in a general item. It is typical to change production schedule in order to adapt changes of product variants and quantity. There is a non-linear corresponding relation between product variables and operating variables, and therefore plan rules need to be defined and constrained. Different process operation procedures result in different processing centers, operation time, process status and fixtures. Formalization of general plans rules is expressed as:

Machining center rules: $\left\{N C \mid m c_{j}\right\}$ IF $\left\{P_{\psi} \mid \eta_{i}\right\}$ AND ... OR $\left\{p_{\text {mw }} \mid \eta_{w w}\right\}$

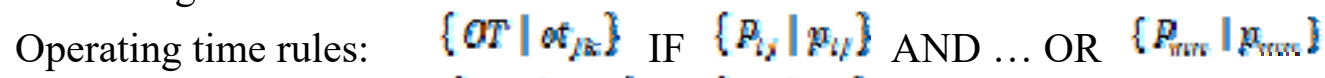

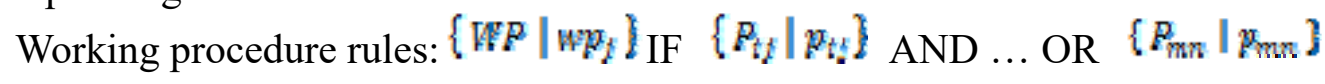

...

Fixture rules: $\left\{A F \mid a f_{j}\right\}$ IF $\left\{F_{t j} \mid p_{t j}\right\}$ AND ... OR $\left\{F_{\min } \mid p_{m n}\right\}$

$\mathrm{WC}$ is the set of machining center $w c_{j}$, $w c_{j}$ represent machining centers which is used by procedure $\mathrm{j}$ for parts production, and it also includes processing equipment or assembly workstation; OT is the set of operating time ${ }^{\alpha t_{k z}}$ of each component on a particular machining center, ${ }^{\circ t_{k z}}$ represent working hours of part $p t_{1}$ when procedure $\mathrm{j}$ takes machining center $\mathrm{k}$; WP is the set of parts procedure $w p_{1}, w p_{1}$ represent procedure $\mathrm{j}$ of part $p t_{\mathrm{j}}$; AF represent the set of auxiliary fixture $a f_{1}$ when machining operation is performed.

(3) General capacity constraint C. Transferability of the production capacity can be considered from a total production capacity perspective. The main parameters and symbols are defined as follows: 1 refers to the total layers; $N_{s}$ is the set of all machining centers in the sth layer of the integrated BOM, $s=1,2, \ldots, l$; For $\forall s, t \in\left\{1,2, \ldots l\right.$ and $s \neq t$, then $N_{s} \cap N_{s}=\equiv ; n_{s}$ is the number of machining centers in the sth layer of the integrated BOM, $v_{s}=\left|N_{s}\right| ; B_{s}$ is the set of the material types in the sth layer of the integrated BOM, $s=1,2, l-1 ; b_{s}$ is the number of the total species of the sth layer, $b_{s}=\left|B_{s}\right| ; d_{s}$ is the index numbers of materials in the sth layer, $d_{s}=1.2 \ldots b_{x} ; k_{s} \in N_{s}, k_{s=14} \in N_{s=14}, d_{s} \in B_{s} ; a_{h_{s} h_{s+1} \mathbb{N}_{s}}^{(s)}$ is the numbers of the materials or components that is provided from the sth layer to the $s+1$ th layer; $\varphi_{\mathbb{R}_{g}}^{[S]}$ is the biggest productivity

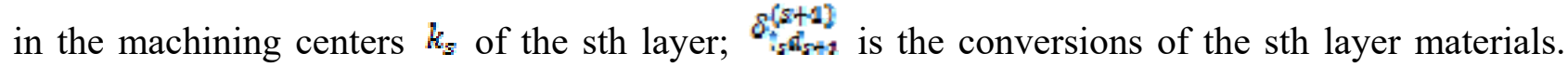
Therefore, it is necessary to meet the following requirements during the execution of the production plan.

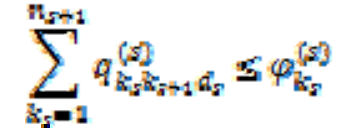

$$
\begin{aligned}
& \forall s \in\{1,2, \ldots, l-1\}, k_{S} \in N_{S}
\end{aligned}
$$

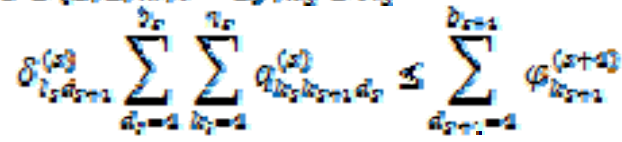

$$
\begin{aligned}
& \forall s \in\{1,2, \ldots, l-1\}, \hat{K}_{s+1} \in N_{s+1}, d_{s} \in B_{s}, d_{s+1} \in B_{s+1}
\end{aligned}
$$

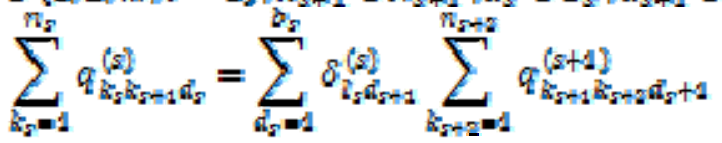

$$
\begin{aligned}
& \forall s \in\{1,2, \ldots, l-2\}, k_{s+1} \in N_{s+1}, d_{s} \in B_{s}, d_{s+1} \in B_{s+1}
\end{aligned}
$$

The constraints of production capacity are considered in the equation (1) and equation (2). The equation (3) emphasizes the constraints of production continuity.

(4) General machining operation $\mathrm{O}$. The set $\left[o_{i}\right\}$ of some operating variables can be represented by a general processing operations. These operating variables are explained by different process information in each operation. The information may be recognized as attributes of the operation. Thus, a sequence can be used to represent a general operation, denoted as $Q=(F T, W C, O T, W P, A F\rangle$. PT is the set of parts $p t_{\hat{2}}$ to be processed. 
(5) General fitting relationship F. General fitting relationship expresses corresponding relationship between parent parts and sub-member parts in the product family structure, which is a particular BOM relationship. A sequence can be used to represent a general fitting relationship, denoted as $F=\left(F T, F A_{2} R T_{2} B S\right)$. FT refers to the set of assembly tasks $t t_{l}, F A$ represents a series of

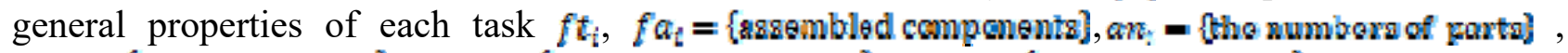

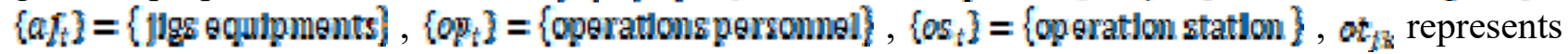
operation time; $R T$ represents the set of assembly mapping relations $r t_{i}$ from resource set to task set; $B S$ represents sequence relationships of the various assembly tasks. Complex generic BOM must be broken in order to better refine the relationship between assembly tasks and resource. Therefore, this paper introduces the concept of decomposition rules to define a certain relationship between the parameter values of parent and child products variables. Formalization of decomposition rules is expressed as:

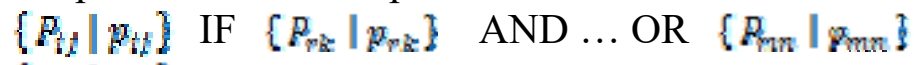

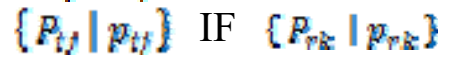

(6) General parts real-time process state set E. It is used to describe real-time statuses of materials and parts machining and assembly process information. Hexadecimal number can not only conveniently be converted to decimal number that can be more easily manipulated by individuals, but also be converted into a binary computer operation. This paper adopts the top eleven of hexadecimal numbers to describe processing information from the beginning (corresponding hexadecimal number is 0 ) to completion of processing (corresponding hexadecimal number is $A$ ), denoted as $E-\left[x_{n-1}, x_{n-g}, \ldots, x_{2} x_{n}\right]$. The values of $x_{l}(l=0,1, n-1)$ indicate the state of processing and assembling in the ith procedure of materials and components. $x_{t} \equiv\{0,1,2, \ldots, d\}, n$ refers to the total numbers of procedure of effective materials and components processing. $x_{t}=0$ represents that there are not processing and assembly for material and components; $x_{t}=1$ represents that ten percent of the workload is done by the $i$-procedure of materials and components; $x_{1}=2$ represents that twenty percent of the workload is done by the $i$-procedure of materials and components; $\ldots ; x_{1}=A$ represents that the $i$-procedure of materials and components process is finished.

\section{Case application}

As mentioned, contact characteristics between BOM and BOP are required materials in each operation, so this paper defines diversity parameters to distinguish different operating variables by common parts and components of general machining process. A common processing operation can share the same set of diversity parameters and their values to link universal parts, which can feed material timely when the components is missing. For example, material and process of "bearing sleeve" variables and "suspension beam -"variables have different constraints, when locomotive manufacture enterprises assemble the "suspension beam I "(case is derived from Part-A of figure 1). According to the sequence definition form of general processing operations is given above, a specific operation variant can be defined as $\mathrm{M}_{1}^{*} \sim$ (bearing sleeve (steel sheets10-Q345E, welding + finishing), $\left.W C-M 2_{1}^{*}, 10.5+4.5, \mathrm{~B} 1001 \mathrm{ZND} 1, \mathrm{M} 2-\mathrm{FS}_{1}^{*}\right)$. The special general machining operation is shown in table 1. 
Table.1. General machining operation case of integrated BOM model

\begin{tabular}{|c|c|c|c|c|c|c|c|}
\hline \multirow{2}{*}{$\begin{array}{l}\text { general } \\
\text { machining } \\
\text { operation } \\
\{Q\}\end{array}$} & \multicolumn{7}{|c|}{ parameter of set-valued } \\
\hline & $\begin{array}{l}\text { components } \\
\left\{p t_{t}\right]\end{array}$ & $\begin{array}{l}\text { work } \\
\text { center } \\
\left\{w \sigma_{j}\right\}\end{array}$ & $\begin{array}{l}\text { operation time } \\
\left.\left\{\sigma_{t}\right\}\right][\mathrm{min}]\end{array}$ & \multicolumn{2}{|c|}{ process state $\left\{\mu s_{t / 2}\right\}$} & $\begin{array}{l}\operatorname{machining} \\
\operatorname{process}\left\{w p_{l}\right\}\end{array}$ & $\begin{array}{l}\text { assembling } \\
\text { fixture }\{a f:\}\end{array}$ \\
\hline \multirow{2}{*}{$\begin{array}{l}\text { plate } \\
\text { processing } \\
\text { (011) }\end{array}$} & \multirow[t]{2}{*}{ plate } & \multirow{2}{*}{$\begin{array}{l}W C-M L_{1}^{1} \\
W C-M L_{2}^{2}\end{array}$} & \multirow{2}{*}{$\begin{array}{l}Q T_{1}^{4}=8.5+8.0 \\
O T_{T}=8.5-2.0\end{array}$} & texture $\left(R_{19}\right)$ & \multirow{2}{*}{ 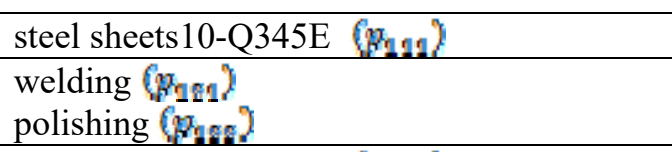 } & \multirow{2}{*}{$\begin{array}{l}\text { B1001ZND9 } \\
(\mathrm{W}-\mathrm{Z})\end{array}$} & \multirow{2}{*}{ ML - FS1 } \\
\hline & & & & process $\left(P_{\mathrm{Ag}}\right)$ & & & \\
\hline \multirow{2}{*}{$\begin{array}{l}\text { bearing } \\
\text { sleeve } \\
\text { processing } \\
\text { (MI) }\end{array}$} & \multirow[t]{2}{*}{$\begin{array}{l}\text { bearing } \\
\text { sleeve }\end{array}$} & \multirow{2}{*}{$\begin{array}{l}W C-M 2 \\
W C-M 2 \\
W C-M 2 \\
W C-M 2\end{array}$} & \multirow{2}{*}{ 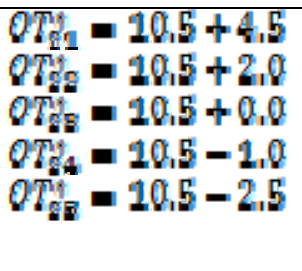 } & texture $\left(R_{R_{1}}\right)$ & 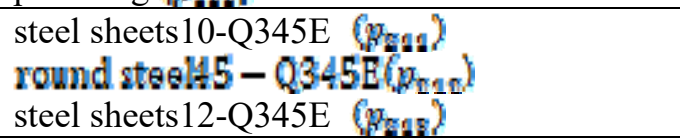 & \multirow{2}{*}{$\begin{array}{l}\text { B1001ZND9 } \\
\text { (W-Z) } \\
\text { B1001ZND1 } \\
((Z)-X-Z) \\
\text { B1001ZM12 } \\
\text { W- (Z)-X-Z }\end{array}$} & \multirow{2}{*}{$\begin{array}{l}M 2-F S 1 \\
M 2-F 51 \\
M 2-F 81 \\
M 2-F 51\end{array}$} \\
\hline & & & & process $\left(P_{g g}\right)$ & $\begin{array}{l}\text { polishing + finishing }\left(p_{z=2}\right) \\
\text { flaw detection }\left(y_{\text {ras }}\right) \\
\text { welding + finishing }\left(p_{\text {gas }}\right)\end{array}$ & & \\
\hline \multirow[t]{2}{*}{$\begin{array}{l}\text { suspension } \\
\text { beam - } \\
\text { processing } \\
\text { (ODS) }\end{array}$} & \multirow[t]{2}{*}{$\begin{array}{l}\text { suspension } \\
\text { beam - }\end{array}$} & \multirow[t]{2}{*}{$\begin{array}{l}W C-M B \\
W C-M 3 \\
W C-M B \\
W C-M B\end{array}$} & \multirow[t]{2}{*}{ 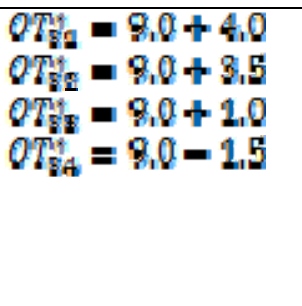 } & texture $\left(f_{\mathrm{b}_{1}}\right]$ & $\begin{array}{l}\text { steel sheets10-Q345E (pras) } \\
\text { steel pipe D-2-100X60X5.6-Q345E (pras }) \\
\text { steel Q345E }\left(p_{\mathrm{g}}\right)\end{array}$ & \multirow[t]{2}{*}{$\begin{array}{l}\text { B1001ZND9 } \\
\text { (W-Z) } \\
\text { B1001ZND1 } \\
((\mathrm{Z})-\mathrm{X}-\mathrm{Z})\end{array}$} & \multirow[t]{2}{*}{$\begin{array}{l}M B-F B 1 \\
M B-F \$ 2 \\
M B-F 51\end{array}$} \\
\hline & & & & process $\left(\mathrm{Ag}_{\mathrm{zg}}\right)$ & 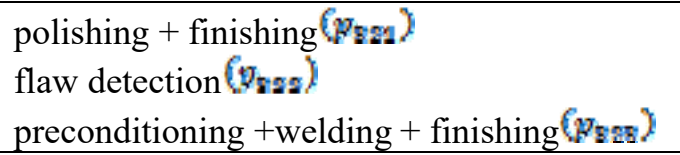 & & \\
\hline \multirow{2}{*}{$\begin{array}{l}\text { suspension } \\
\text { beam steel } \\
\text { pipe } \\
\text { processing } \\
\text { (MA) }\end{array}$} & \multirow[t]{2}{*}{ steel pipe } & \multirow[t]{2}{*}{$\begin{array}{l}\text { WC-MAt } \\
\text { WE-MAt }\end{array}$} & \multirow[t]{2}{*}{$\begin{array}{l}O T_{A 1}^{4}=8,0+2.5 \\
Q T_{A L}^{4}=8,0+2.5\end{array}$} & texture $\left(R_{t a}\right)$ & $\begin{array}{l}\text { steel pipe D-2-120X60X6.3-Q345E }\left(\mathrm{p}_{4 \mathrm{II}}\right) \\
\text { steel sheets 22-Q345E }\left(\mathrm{q}_{4 \mathrm{II}}\right)\end{array}$ & \multirow[t]{2}{*}{$D$} & \multirow[t]{2}{*}{$\phi$} \\
\hline & & & & process $\left(R_{\text {mas }}\right)$ & $\phi$ & & \\
\hline \multirow[t]{2}{*}{$\begin{array}{l}\text { suspension } \\
\text { beam } \\
\text { process } \\
\text { (AI) }\end{array}$} & \multirow[t]{2}{*}{$\begin{array}{l}\text { suspension } \\
\text { beam }\end{array}$} & \multirow[t]{2}{*}{$\begin{array}{l}W C-A 1_{1} \\
W C-A 2\end{array}$} & \multirow[t]{2}{*}{$\begin{array}{l}Q T_{\mathrm{g}}^{4}=7.5+2.0 \\
Q T_{\mathrm{R}}^{4}=7.5+0.5 \\
Q T_{\mathrm{W}}^{4}=7.5-0.5\end{array}$} & $\begin{array}{l}\text { material } \\
\text { constraint } \\
\left(p_{a z}\right)\end{array}$ & 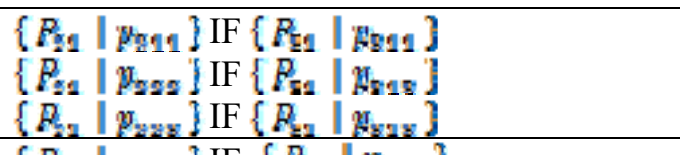 & \multirow[t]{2}{*}{$\begin{array}{l}\text { B1001ZND9 } \\
(\mathrm{W}-Z) \\
\text { B1001ZND1 } \\
((\mathrm{Z})-\mathrm{X}-\mathrm{Z})\end{array}$} & \multirow[t]{2}{*}{$\begin{array}{l}A 1-F S 1 \\
A 1-F S A \\
A 1-F S 1 \\
A 1-F S 1\end{array}$} \\
\hline & & & & $\begin{array}{l}\text { process } \\
\text { constraint } \\
\left(P_{a 2}\right)\end{array}$ & 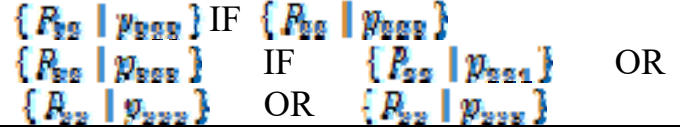 & & \\
\hline
\end{tabular}




\section{Conclusions}

The product data and production data are united in the integrated BOM model by material relationship of BOM and BOP. The set of diversity parameters and their values is used to ensure consistency of the product and process variables. In addition, all generic products variables are assumed to follow the same product structure and the same operation process, which means that there must be a general product structure and a process structure among the product family. The diversity just is included in different variables of general structure. Based on this model, the large complex product manufacturing enterprises can more flexibly arrange the total production plan and assembly production process according to their capacity in order to better respond to continuous changing of market demand.

\section{Acknowledgement}

In this paper, the research was sponsored by the project of National Science and Technology Support Program, China(2015BAF08B02) and the State Key Program of NSFC(71172137).

\section{References}

[1] Yunkung Chung, Fischer, G.W. A conceptual structure and issues for an object-oriented Bill of Materials data model [J]. Computers \& Industrial Engineering, 1994, 26(2):321-339.

[2] Garcia Sabater Jose P, Maheut Julien, Marin Garcia Juan A. A new formulation technique to materials and operations planning: the generic materials and operations planning (GBOM) problem [J]. European Journal of Industrial Engineering, 2013, 7 (2):119-147.

[3] Wang Yang, Liu Xiaobing. Unified product BOM model oriented to concurrent engineering [J].Application Research of Computers, 2010, 27(8): 2984-2990.

[4] Bo Hongguang, Huang Wenqiu, Chen Shengwu. Bill of Manufacturing Resources Model Based on Production Process for Steelmaking Enterprises [J]. Industrial Engineering and Management, 2011, 16 (16): 50-54.

[5] Bo Hongguang, Zhang Nan, Liu Xiaobing. Batch-based bill of material integration technologies for process industry[J]. Computer Integrated Manufacturing Systems, 2010, 16 (1): 165-173.

[6] Mohamed Kashkoush, Hoda EIMaraghy. Product family formation by Bill-of-Materials trees[J]. CIRP Journal of Manufacturing Science and Technology, 2016, 12:1-13. 